\title{
Effect of NOS1 regulating ABCG2 expression on proliferation and apoptosis of cervical cancer cells
}

\author{
MINGDE DING ${ }^{1}$, HUI ZHANG ${ }^{1}$, LEI LIU $^{2}$ and RUILAN LIANG ${ }^{1}$ \\ Departments of ${ }^{1}$ Gynaecology and ${ }^{2}$ Pathology, \\ Affiliated Hospital of Taishan Medical University, Taian, Shandong 271000, P.R. China
}

Received April 27, 2018; Accepted November 5, 2018

DOI: 10.3892/ol.2018.9786

\begin{abstract}
The expression of nitric oxide synthase 1 (NOS1) and adenosine triphosphate-binding cassette sub-family $\mathrm{G}$ member 2 (ABCG2) in cervical cancer tissues was investigated. The messenger ribonucleic acid (mRNA) levels of NOS1 and ABCG2 in 40 cervical cancer specimens and 20 normal cervical specimens were detected via reverse transcription-polymerase chain reaction, and the correlation between them was analyzed via Pearson's correlation analysis. The protein expression levels were detected via western blotting. Moreover, the regulatory mode between NOS1 and ABCG 2 and the effects on proliferation and apoptosis of cervical cancer cells were analyzed using the lentiviral transfection technique. The mRNA levels of NOS1 and ABCG2 in the cervical cancer group were significantly increased compared with those in the normal cervical control group $(\mathrm{P}<0.05)$. There was a positive correlation between NOS1 and ABCG2 mRNA expression levels in cervical cancer tissues $(\mathrm{r}=1.246, \mathrm{P}=0.014)$. HeLa and $\mathrm{C}-33 \mathrm{~A}$ cell lines with relatively high expression levels of NOS1 and ABCG2 were selected for the in vitro study. After interference in the NOS1 expression in HeLa and C-33A cells with sh-NOS1, the protein expression of ABCG2 was also decreased. However, the protein expression level of NOS1 remained unchanged after interference in the ABCG2 expression $(\mathrm{P}<0.05)$. After interference in the NOS1 expression, the proliferation capacities of $\mathrm{HeLa}$ and $\mathrm{C}-33 \mathrm{~A}$ cells were significantly decreased, but the apoptosis levels were obviously increased $(\mathrm{P}<0.05)$. The mRNA expression of NOS1 and ABCG2 in cervical cancer tissues is significantly increased. NOS1, as an upstream signal regulator of ABCG2, regulates the growth and apoptosis of tumor cells. Both NOS1 and ABCG2 are important proliferation-promoting oncogenes in cervical cancer, which are expected to provide a certain theoretical basis for the treatment of cervical cancer.
\end{abstract}

Correspondence to: Dr Mingde Ding, Department of Gynaecology, Affiliated Hospital of Taishan Medical University, 706 Taishan Avenue, Taian, Shandong 271000, P.R. China

E-mail: dingmingde2018@163.com

Key words: NOS1, ABCG2, cervical cancer, proliferation, apoptosis

\section{Introduction}

There are more than 500,000 new cases and 275,000 deaths of cervical cancer every year, and the morbidity and mortality rates of cervical cancer rank 3rd and 4th in the cancer in women around the world $(1,2)$. Cervical cancer is mainly caused by the infection of oncogenic human papilloma virus (HPV). Compared with other cancers, HPV-based detection is the most effective screening means for cervical cancer (3). However, conventional operation and chemoradiotherapy are still dominated in the treatment of cervical cancer. Investigating the molecular mechanisms of occurrence and progression of cervical cancer and searching new targets are still research hotspots.

Nitric oxide (NO), as one of the smallest bioactive products known in mammalian cells, can be produced by almost all cells (4). NO is produced by inducible and endothelial NO synthase (NOS) in the NOS family (5). Studies have found that the NOS expression is generally enhanced in a variety of tumor tissues, and three kinds of different NOS subtypes, namely neuronal (N)-type, inducible (I)-type and endothelial (E)-type, have been identified currently. These synthases possess different positions, regulation abilities, catalytic properties and sensitivity to inhibitor, which can promote tumor proliferation, metastasis and resistance to chemotherapy drugs (6,7). NOS1, the N-type NOS, can secrete NO in a lower concentration, promoting tumor growth and angiogenesis (8). NOS2 mainly exists in mastocytes, macrophages and neutrophils, which, after being activated by external stimuli, can produce NO in a high concentration, thus inducing inflammation-related reactions and promoting or affecting tumor growth (9). NO plays an important role as a biological medium in vascular biology and inflammation. Moreover, studies have demonstrated that the low-concentration NO promotes tumor growth, while the high-concentration NO is the free radical that inhibits cell proliferation and induces apoptosis, with a biological effect of suppressing tumor growth (10). Currently, however, the expression level and biological effect of NOS, an important catalytic enzyme for NO production, in cervical cancer have not been fully clarified yet.

Adenosine triphosphate (ATP)-binding cassette sub-family G member 2 (ABCG2), also known as breast cancer resistance protein, is correlated with the drug resistance in a variety of tumors, which is usually deleted or expressed at a low level in 
the pancreas. According to recent studies, ABCG2 is highly expressed in pancreatic cancer cells and promotes cell survival via changing the cell epigenetic program (11). Moreover, the ABCG2 expression is significantly increased in side population cells in gastric cancer and other tumors (12). However, the ABCG2 expression in cervical cancer is not clear, and the mechanism of normally regulating ABCG2 expression is poorly understood.

In this study, NOS1 and ABCG2 messenger ribonucleic acid (mRNA) levels were detected in 40 cases of human cervical cancer tissues and 20 cases of benign cervical tissues, and the correlation between NOS1 and ABCG2 mRNA levels was analyzed. Besides, lentivirus transfection technique was used to interfere in the expression of NOS1 and ABCG2 in cervical cancer cells, so as to investigate its effects on the proliferation and apoptosis of cervical cancer cells and the specific regulatory mechanism.

\section{Materials and methods}

Clinical specimens. A total of 40 patients with cervical cancer who had not received any treatment prior to the study in the Department of Gynaecology of Affiliated Hospital of Taishan Medical University (Taian, China) from September 2015 to March 2017 were randomly collected. The enrolled patients were aged 37-63 years with an average of 42.4 years. Another 20 paraffin-embedded specimens of normal cervical tissues were collected from the Pathology Department of Affiliated Hospital of Taishan Medical University. This study was approved by the Ethics Committee of the hospital, and all patients enrolled in the study signed the informed consent.

Detection of NOS1 and ABCG2 $m R N A$ levels via reverse transcription-quantitative polymerase chain reaction $(R T-q P C R)$. The total RNA was extracted from cells using the TRIzol method, and reverse transcribed into complementary deoxyribonucleic acid (cDNA) using the reverse transcription kit (Gene Copoeia, Guangzhou, China). The mRNA expression levels of SYBR-Green (Thermo Fisher Scientific, Inc., Waltham, MA, USA) NOS1 and ABCG2 in cells were detected via RT-qPCR, and glyceraldehyde-3-phosphate dehydrogenase (GAPDH) was used as the internal reference. Reaction conditions were as follows: pre-degeneration at $95^{\circ} \mathrm{C}$ for $15 \mathrm{~min}, 95^{\circ} \mathrm{C}$ for $5 \mathrm{sec}$, annealing at $64^{\circ} \mathrm{C}$ for $30 \mathrm{sec}$, a total of 40 cycles. The primers which used were: NOS1 sense, 5'-GAATACCAGCCTGATCCCTGGAA-3' and anti-sense, 5'-TCCAGGAGGGTGTCCACAGCGTG-3' (599 bp in length of product). ABCG2 sense, 5'-AATACATCAGCGGA TACTACAGAG-3' and anti-sense, 5'-AGCCACCAT CATAAAGGGGTAAACAT-3' (472 bp in length of product). GAPDH sense, 5'-CGGAGTCAACGGATTTGGTCGTAT-3' and anti-sense, 5'-AGCCTTCTCCATGGTGGTGAAGAC-3'. The relative expression level of mRNA in each index was calculated using the $2^{-\Delta \mathrm{Cq}}$ method $[\Delta \mathrm{Cq}=\mathrm{Cq}$ (target gene) $-\mathrm{Cq}$ (GAPDH)] (13).

Cell culture. Human cervical cancer cell lines (CaSki, HeLa, HCE1 and C-33A) were purchased from the Cell Bank of the Chinese Academy of Sciences (Wuhan, China). Cells were cultured in the high-glucose Dulbecco's modified Eagle's medium (DMEM) containing 10\% fetal bovine serum, and added with $100 \mu \mathrm{g} / \mathrm{ml}$ streptomycin and $100 \mathrm{IU} / \mathrm{ml}$ penicillin. The medium was placed in an incubator with $5 \% \mathrm{CO}_{2}$ and humidity of $95 \%$ at $37^{\circ} \mathrm{C}$.

Western blotting. The protein was extracted from the 6-well plate, with protein extraction kit (Invent Biotechnologies, Inc., Plymouth, MA, USA) and the protein concentration was detected using the bicinchoninic acid (BCA) protein concentration assay kit (Beyotime Institute of Biotechnology, Haimen, China). Then $40 \mu \mathrm{g}$ total proteins were separated via $10 \%$ sodium dodecyl sulphate-polyacrylamide gel electrophoresis (SDS-PAGE), transferred onto a polyvinylidene fluoride (PVDF) membrane, and blocked in $5 \%$ skim milk at $20^{\circ} \mathrm{C}$ for $1 \mathrm{~h}$. The mouse anti-human NOS1 or ABCG2 (1:2,000; R\&D Systems, MN, USA; article no: 85327, FAB995P) and GAPDH primary monoclonal antibodies $(1: 1,000$; cat. no. ab8245; Abcam, Cambridge, UK) were incubated at $4^{\circ} \mathrm{C}$. The protein band was incubated with the corresponding horseradish peroxidase-labeled secondary antibody (1:2,000; cat. no. A0216; Beyotime Institute of Biotechnology, Guangzhou, China) at room temperature for $1 \mathrm{~h}$. The membrane was visualized using the enhanced chemiluminescence (ECL) detection system (Bio-Rad Laboratories, Inc., Hercules, CA, USA), and the gray scale was analyzed using a gel analyzer. (Bio-Rad Laboratories, Inc.).

Lentivirus transfection. One pair of specific short hairpin RNA (shRNA) target sequences for human NOS1 and ABCG2 genes, and one negative control shRNA sequence not interfering in any human gene expression were designed and synthesized by Shanghai GenePharma Co., Ltd., Shanghai, China. Sequences were constructed into the pHBLV-U6-ZsGreen-Puro lentiviral vector, followed by transfection using the lentiviral plasmid system. HeLa and C-33A cells were inoculated into a 6 -well plate at a density of $5 \times 10^{5} /$ well. When $50-60 \%$ cells were fused, the lentivirus was added for infection. The original medium was replaced with the puromycin-containing medium once every $24 \mathrm{~h}$ for screening. Then cells were digested with $0.25 \%$ trypsin, followed by passage once every 2 days. Finally, cells were collected after passaged 3-4 times. NOS1-targeted shRNA sequences: sense, 5'-GGCCAUACUCUUAGUTT-3' and antisense, 5'-AU UUGAGUAUUUCAGCUCCTT-3'. The shRNA sequence targeting ABCG2: sense strand 5'-TGTCAGACUCCAGAGU TA-3'; antisense strand 5'-GATTAUAUCCTGTAGGAG-3'. Negative control (sh-vector) sequences: sense, 5'-UUCUCCGA ACGUGUCACGUTT-3' and antisense, 5'-ACGUGACACGU UCGGAGAATT-3'.

Cell proliferation and apoptosis detection. Colony-forming assay: HeLa and C-33A cells in good growth status were inoculated into the 6 -well plate at a density of $5 \times 10^{2} /$ well, and cultured in the incubator with $5 \% \mathrm{CO}_{2}$ at $37^{\circ} \mathrm{C}$ until there were visible cell colonies. Then cells were fixed with $4 \%$ paraformaldehyde for $30 \mathrm{~min}$, stained with crystal violet for $15 \mathrm{~min}$, and photographed under a microscope (Nikon Instrument, NY, USA) and the number of cell colonies was counted.

Detection of apoptosis via flow cytometry: apoptosis was detected using the apoptosis kit (BD Science, Harlingen, 

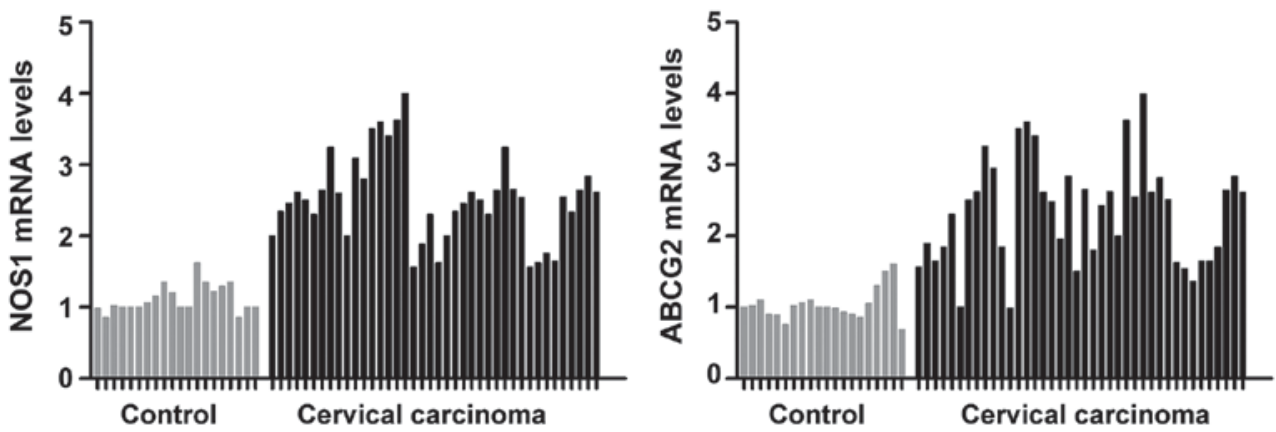

Figure 1. Detection of NOS1 and ABCG2 mRNA levels in normal cervical tissues and cervical cancer tissues via RT-qPCR. The mRNA levels of NOS1 and ABCG2 in the cervical cancer group are significantly increased compared with those in the normal cervical control group, and the mean differences are 2.63 and 2.02 times, respectively $(\mathrm{P}<0.05)$. NOS1, nitric oxide synthase 1; ABCG2, adenosine triphosphate-binding cassette sub-family G member 2.

Chicago, USA). At 2 days after transfection, cells were digested and centrifuged at $3,000 \mathrm{xg}$ for $8 \mathrm{~min}$ at $4^{\circ} \mathrm{C}$, washed twice with iced phosphate-buffered saline (PBS), resuspended in $100 \mu \mathrm{l}$ IX Bing buffer, and added with $5 \mu \mathrm{l}$ propidium iodide (PI) and Annexin V, respectively, followed by incubation at room temperature in the dark for $15 \mathrm{~min}$. Then the mixture was sent to the Scientific Research Center of Affiliated Hospital of Taishan Medical University for detection on the machine within $1 \mathrm{~h}$. Apoptotic rate = early apoptotic rate + late apoptotic rate.

Statistical analysis. Statistical Product and Service Solutions (SPSS) 19.00 software (IBM Corp., Armonk, NY, USA) was used for the analysis of the data in this study. Measurement data were presented as mean \pm standard deviation, the differences in indexes between the two groups were compared and analyzed using t-test, and the correlation between NOS1 and ABCG2 mRNA expression levels in cervical cancer tissues was analyzed via Pearson's correlation analysis. $\mathrm{P}<0.05$ was considered to indicate a statistically significant difference.

\section{Results}

Detection of NOS1 and ABCG2 mRNA levels in normal cervical tissues and cervical cancer tissues via RT-qPCR. The mRNA levels of NOS1 and ABCG2 in 20 cases of normal cervical tissues and 40 cases of cervical cancer tissues were quantitatively detected via RT-qPCR. It was found that the mRNA levels of NOS1 and ABCG2 in cervical cancer group were significantly increased compared with those in the normal cervical control group, and the mean differences were 2.63 and 2.02 times, respectively $(\mathrm{P}<0.05)$ (Fig. 1).

Detection of correlation between NOS1 and ABCG2 mRNA levels in cervical cancer tissues. The mRNA expression levels of NOS1 and ABCG2 in 40 cases of cervical cancer tissues were analyzed. Pearson's correlation analysis revealed that there was a positive correlation between NOS1 and ABCG2 mRNA expression levels in cervical cancer tissues $(\mathrm{r}=1.246$, $\mathrm{P}=0.014$ ) (Fig. 2).

Expression of NOS1 and ABCG2 protein in cervical cancer cell lines. Results of western blotting showed that NOS1 was expressed in CaSki, HeLa, HCE1 and C-33A cells in cervical

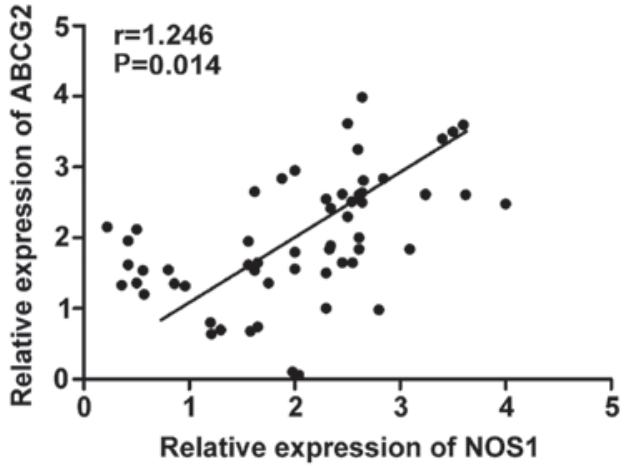

Figure 2. Detection of correlation between NOS1 and ABCG2 mRNA levels in cervical cancer tissues. Pearson's correlation analysis reveals that there is a positive correlation between NOS1 and ABCG2 mRNA expression levels in cervical cancer tissues $(\mathrm{r}=1.246, \mathrm{P}=0.014)$. NOS1, nitric oxide synthase 1 ; ABCG2, adenosine triphosphate-binding cassette sub-family $\mathrm{G}$ member 2 .

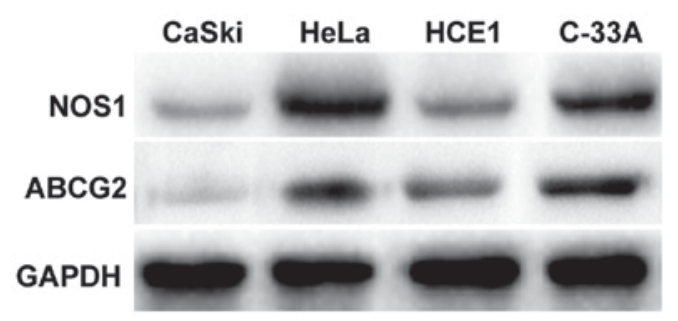

Figure 3. Expression of NOS1 and ABCG2 protein in cervical cancer cell lines via western blotting. NOS1, nitric oxide synthase 1; ABCG2, adenosine triphosphate-binding cassette sub-family G member 2 .

cancer, among which the expression levels are relatively higher in HeLa and C-33A cell lines (Fig. 3).

Detection of regulatory relationship between NOS1 and $A B C G 2$ via western blotting. HeLa and C-33A cell lines with relatively high expression of NOS1 and ABCG2 were selected, and the regulatory relationship between NOS1 and $\mathrm{ABCG} 2$ in cervical cancer cells was detected using the lentiviral plasmid transfection technique. First, after interference in the NOS1 expression in HeLa and C-33A cells with sh-NOS1, it was found that the protein expression of ABCG2 was also decreased. Furthermore, the protein expression level of NOS1 remained unchanged after interference in the ABCG2 expression, suggesting that NOS1 may be an 


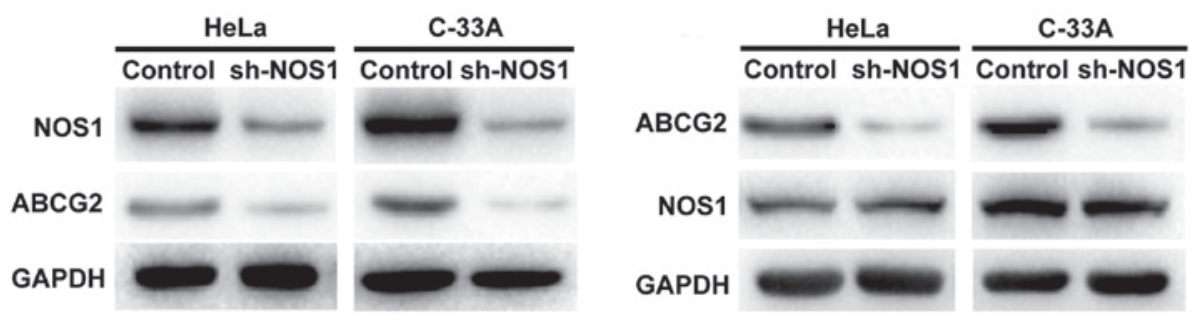

Figure 4. Detection of regulatory relationship between NOS1 and ABCG2 via western blotting. NOS1, nitric oxide synthase 1; ABCG2, adenosine triphosphate-binding cassette sub-family G member 2 .
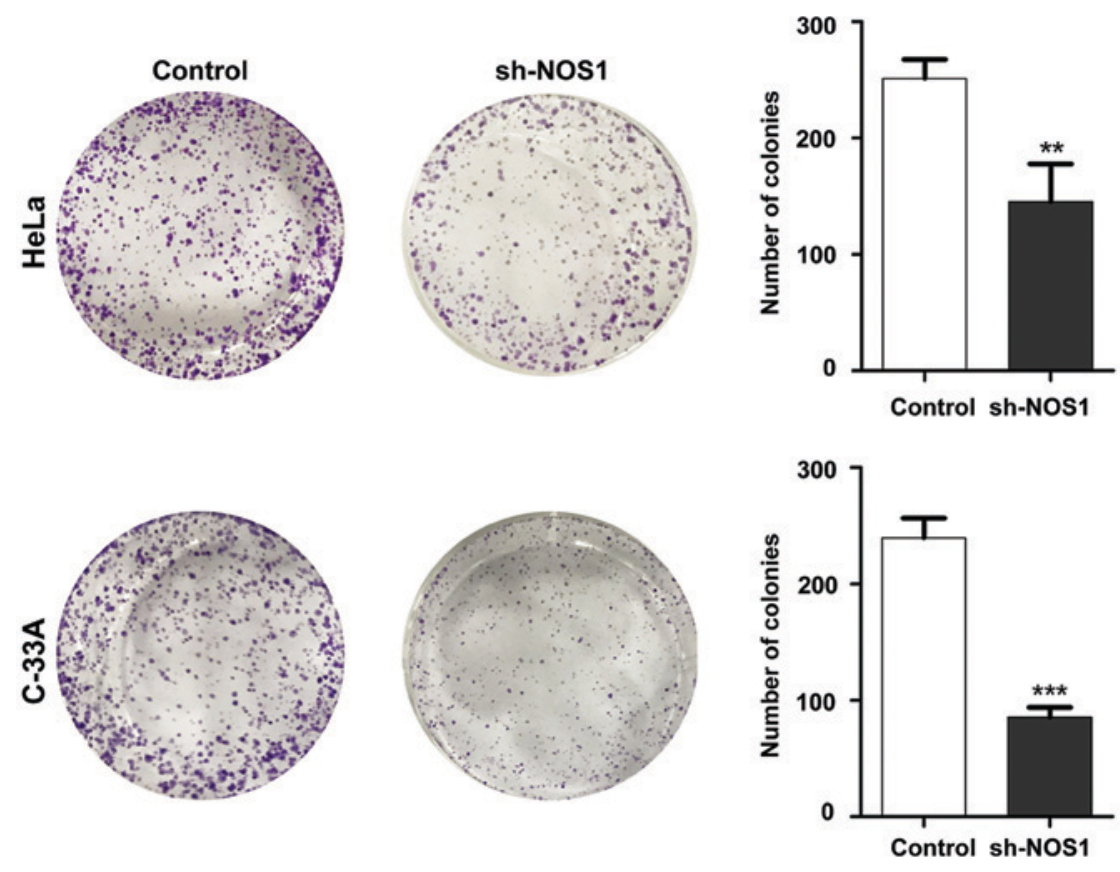

Figure 5. NOS1 silencing inhibits proliferation capacity of cervical cancer cells via colony-forming assay. ${ }^{* *} \mathrm{P}<0.01,{ }^{* * *} \mathrm{P}<0.001$ vs. the control group. NOS1 silencing significantly reduces the proliferation capacities of HeLa and C-33A cells. NOS1, nitric oxide synthase 1.
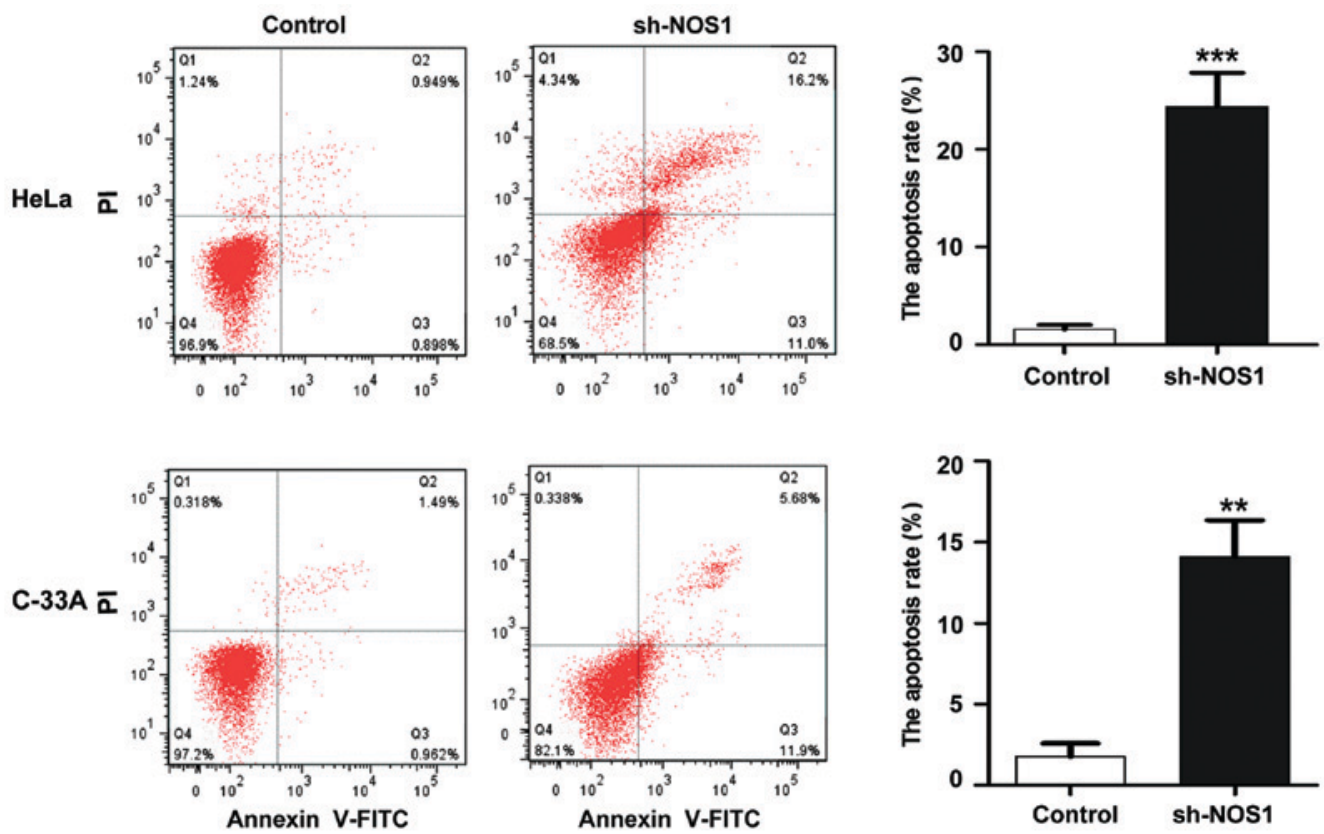

Figure 6. NOS1 silencing promotes the apoptosis level of cervical cancer cells. ${ }^{* *} \mathrm{P}<0.01,{ }^{* * *} \mathrm{P}<0.001$ vs. the control group. Compared with those in the control group, the apoptosis levels are obviously increased after NOS1 silencing (HeLa, $1.45 \pm 0.72$ vs. $24.75 \pm 6.27 \%$; C-33A, $2.11 \pm 1.16$ vs. $17.24 \pm 7.82 \%$ ). NOS1, nitric oxide synthase 1 . 
upstream regulatory molecule of $\mathrm{ABCG} 2$ in cervical cancer cells (Fig. 4).

Detection of NOS1 silencing effect on cell proliferation capacity via colony-forming assay. After cell lines with stable NOS1 interference were established, the effect of NOS1 on proliferation of cervical cancer cells was detected via colony-forming assay. Results demonstrated that compared with those in the control group, the number of proliferating HeLa cells and C-33A cells in the sh-NOS1 group was significantly decreased, and there were statistically significant differences $(\mathrm{P}<0.05)$ (Fig. 5).

Detection of changes in apoptosis level after NOS1 silencing via flow cytometry. After the NOS1 expression silencing in HeLa and C-33A cells, changes in the apoptosis level were detected via flow cytometry. Compared with those in the control group, the apoptosis levels were obviously increased after NOS1 silencing (HeLa, $1.45 \pm 0.72$ vs. $24.75 \pm 6.27 \%$; C-33A, $2.11 \pm 1.16$ vs. $17.24 \pm 7.82 \%$ ), displaying statistically significant differences $(\mathrm{P}<0.05)$ (Fig. 6).

\section{Discussion}

In recent years, studies have demonstrated that NO, as a kind of gas signal molecule, affects the biological functions of a variety of malignant tumors. Fionda et al found that NO can lead to DNA damage, cause mutation and induce genetic lesions (14). Fahey and Girotti found that NO promotes tumor progression through mediating key processes, such as angiogenesis, tumor cell growth and invasion (15). However, NO in a low concentration has a protective effect on mouse colon cancer in some tumor immune responses (16). NOS is an enzyme that catalyzes the NO biosynthesis. Due to the short half-life of NO, it exerts the biological effect entirely depending on NOS. It has already been verified that the main effect form of NOS1 is the transient synthesis of NO in a lower concentration, while that of NOS2 is the catalyzed synthesis of persistent NO in a sustainably high concentration (17).

The related gene to the risk of prostate cancer NOS1 was also reported in a small case-control study involving 125 cases (5). It has been proved that the expression of NOS1 is remarkably increased in several kinds of human cancer specimens and precancerous chronic inflammation specimens (18). Recently, a global genetic screening experiment revealed that NOS2 and NOS3 gene polymorphisms are correlated with the risk of prostate cancer, especially invasive cancer, in Caucasians and African-Americans (19). Wang et al studied the correlations of NOS1 repeat polymorphism with high histological grading of prostate cancer and shedding of circulating tumor cells in the blood. These findings are supported by evidence, in other words, NOS1 promotes tumor growth rate, vascular density and invasiveness, and maintains the blood supply of prostate tumor (20). Moreover, there are studies showing that in p53-mutated tumor cells, NOS increases the expression of vascular endothelial growth factor and promotes tumor growth, indicating that the tumor-killing activity of $\mathrm{NO}$ depends on the state of p53 (21).

Overexpression of ABCG2 promotes migration and invasion of a variety of tumors. Previous studies manifested that
AGBC2 may be regulated by DNA methylation, 5'-untranslated region mutation, histone modifications, cytokines and growth factors, such as TGF- $\beta$, TNF- $\alpha$ and IL1- $\beta 2$ (21). According to recent studies, in addition to affecting the chemotherapy sensitivity of various malignant tumors, ABCG2, as a transporter of glutathione, plays an important role in intracellular redox balance (22). Moreover, it was found that ABCG2 can limit the intake of chlorophyllin A and porphyrins, thereby affecting the singlet oxygen production in cells, and leading to DNA hydrolysis and apoptosis (23). Studies have confirmed that NOS enhances the activity of antioxidation-related transcription factors (HIF-1 $\alpha$ and Nrf-2), and upregulates the transcription of antioxidant substance SOD through its product NO, thus enhancing the tolerance of tumor cells to the hypoxia environment after chemotherapy, and reducing tumor cell apoptosis (24). However, there has been no report on whether NOS1 and multidrug resistance gene ABCG2 are involved in the proliferation and apoptosis of cervical cancer cells.

In this study, the mRNA levels of NOS1 and ABCG2 in 20 cases of benign cervical tissues and 40 cases of human cervical cancer tissues were studied. It was found that the mRNA levels of NOS1 and ABCG2 in the cervical cancer group were significantly increased compared with those in the normal cervical control group, and the mean differences were 2.63 and 2.02 times, respectively. Pearson's correlation analysis revealed that there was a positive correlation between NOS1 and ABCG2 mRNA expression levels in cervical cancer tissues $(\mathrm{r}=1.246, \mathrm{P}=0.014)$. To investigate the interaction between NOS1 and ABCG2 in cervical cancer, western blotting was performed for cervical cancer cells (CaSki, HeLa, HCE1 and C-33A), and results manifested that NOS1 and $\mathrm{ABCG} 2$ were expressed in the 4 kinds of cell lines. HeLa and C-33A cell lines with relatively high expression of NOS1 and ABCG2 were selected for the in vitro study. After interference in the NOS1 expression in HeLa and C-33A cells with sh-NOS1, the protein expression of ABCG2 was also decreased. Interestingly, the protein expression level of NOS1 remained unchanged after interference in the ABCG2 expression. According to the above results, it is speculated that NOS1 may be an upstream regulatory molecule of ABCG2 in cervical cancer cells. The proliferation capacities of HeLa and C-33A cells were obviously decreased, but the apoptosis levels were significantly increased after interference in the NOS1 expression, which were consistent with the expected results. However, the specific regulatory molecular mechanisms of NOS1 and ABCG2 still need further study.

In conclusion, the overexpression of NOS1 and ABCG2 was found for the first time in clinical specimens of cervical cancer, and the in vitro experiments showed that the activity of NOS1, as the upstream regulatory molecule of ABCG2, had a significantly negative correlation with tumor cell proliferation. NOS1 and ABCG2 are expected to be new targets for the treatment of cervical cancer, providing new strategies for the clinical treatment of cervical cancer patients.

\section{Acknowledgements}

Not applicable. 


\section{Funding}

No funding was received.

\section{Availability of data and materials}

The datasets used and/or analyzed during the present study are available from the corresponding author on reasonable request.

\section{Authors' contributions}

MD and HZ were responsible for treating patients, RT-qPCR and western blotting. LL helped with the collection of clinical specimens. LL and RL contributed to cell culture and lentivirus transfection. All authors read and approved the final manuscript.

\section{Ethics approval and consent to participate}

The study was approved by the Ethics Committee of Affiliated Hospital of Taishan Medical University (Taian, China) and informed consents were signed by the patients or the guardians.

\section{Patient consent for publication}

Not applicable.

\section{Competing interests}

The authors declare that they have no competing interests.

\section{References}

1. Vaccarella S, Franceschi S, Engholm G, Lönnberg S, Khan S and Bray F: 50 years of screening in the Nordic countries: Quantifying the effects on cervical cancer incidence. Br J Cancer 111: 965-969, 2014

2. Pfaendler KS and Tewari KS: Changing paradigms in the systemic treatment of advanced cervical cancer. Am J Obstet Gynecol 214: 22-30, 2016.

3. Ronco G, Dillner J, Elfström KM, Tunesi S, Snijders PJ, Arbyn M, Kitchener H, Segnan N, Gilham C, Giorgi-Rossi P, et al, International HPV screening working group: Efficacy of HPV-based screening for prevention of invasive cervical cancer: Follow-up of four European randomised controlled trials Lancet 383: 524-532, 2014.

4. Lo Faro ML,Fox B, Whatmore JL, Winyard PG and Whiteman M: Hydrogen sulfide and nitric oxide interactions in inflammation. Nitric Oxide 41: 38-47, 2014

5. Bogdan C: Nitric oxide synthase in innate and adaptive immunity: An update. Trends Immunol 36: 161-178, 2015.

6. King AL, Polhemus DJ, Bhushan S, Otsuka H, Kondo K, Nicholson CK, Bradley JM, Islam KN, Calvert JW, Tao YX, et al: Hydrogen sulfide cytoprotective signaling is endothelial nitric oxide synthase-nitric oxide dependent. Proc Natl Acad Sci USA 111: 3182-3187, 2014.

7. Marigo I, Zilio S, Desantis G, Mlecnik B, Agnellini AHR, Ugel S, Sasso MS, Qualls JE, Kratochvill F, Zanovello P, et al: $\mathrm{T}$ cell cancer therapy requires $\mathrm{CD} 40-\mathrm{CD} 40 \mathrm{~L}$ activation of tumor necrosis factor and inducible nitric-oxide-synthase-producing dendritic cells. Cancer Cell 30: 377-390, 2016.

8. Guo FQ and Crawford NM: Arabidopsis nitric oxide synthase1 is targeted to mitochondria and protects against oxidative damage and dark-induced senescence. Plant Cell 17: 3436-3450, 2005.
9. Ambs S, Merriam WG, Bennett WP, Felley-Bosco E Ogunfusika MO, Oser SM, Klein S, Shields PG, Billiar TR and Harris CC: Frequent nitric oxide synthase-2 expression in human colon adenomas: Implication for tumor angiogenesis and colon cancer progression. Cancer Res 58: 334-341, 1998.

10. Xu W, Liu LZ, Loizidou M, Ahmed M and Charles IG: The role of nitric oxide in cancer. Cell Res 12: 311-320, 2002.

11. Wang F, Xue X, Wei J, An Y, Yao J, Cai H, Wu J, Dai C, Qian Z, $\mathrm{Xu} \mathrm{Z}$, et al: hsa-miR-520h downregulates ABCG2 in pancreatic cancer cells to inhibit migration, invasion, and side populations. Br J Cancer 103: 567-574, 2010.

12. Jiang Y, He Y, Li H, Li HN, Zhang L, Hu W, Sun YM, Chen FL and Jin XM: Expressions of putative cancer stem cell markers $\mathrm{ABCB} 1, \mathrm{ABCG} 2$, and CD133 are correlated with the degree of differentiation of gastric cancer. Gastric Cancer 15: 440-450, 2012.

13. Livak KJ and Schmittgen TD: Analysis of relative gene expression data using real time quantitative PCR and the 2(-Delta Delta C(T)) method. Methods 25: 402 408, 2001.

14. Fionda C, Abruzzese MP, Zingoni A, Soriani A, Ricci B, Molfetta R, Paolini R, Santoni A and Cippitelli M: Nitric oxide donors increase PVR/CD155 DNAM-1 ligand expression in multiple myeloma cells: Role of DNA damage response activation. BMC Cancer 15: 17, 2015.

15. Fahey JM and Girotti AW: Accelerated migration and invasion of prostate cancer cells after a photodynamic therapy-like challenge: Role of nitric oxide. Nitric Oxide 49: 47-55, 2015.

16. Puglisi MA, Cenciarelli C, Tesori V, Cappellari M, Martini M, Di Francesco AM, Giorda E, Carsetti R, Ricci-Vitiani L and Gasbarrini A: High nitric oxide production, secondary to inducible nitric oxide synthase expression, is essential for regulation of the tumour-initiating properties of colon cancer stem cells. J Pathol 236: 479-490, 2015.

17. Wang X, Chandrashekar K, Wang L, Lai EY, Wei J, Zhang G, Wang S, Zhang J, Juncos LA and Liu R: Inhibition of nitric oxide synthase 1 induces salt-sensitive hypertension in nitric oxide synthase $1 \alpha$ knockout and wild-type mice. Hypertension 67: 792-799, 2016.

18. Rabender CS, Alam A, Sundaresan G, Cardnell RJ, Yakovlev VA, Mukhopadhyay ND, Graves P, Zweit J and Mikkelsen RB: The role of nitric oxide synthase uncoupling in tumor progression. Mol Cancer Res 13: 1034-1043, 2015.

19. Wang J, He P, Gaida M, Yang S, Schetter AJ, Gaedcke J, Ghadimi BM, Ried T, Yfantis H, Lee D, et al: Inducible nitric oxide synthase enhances disease aggressiveness in pancreatic cancer. Oncotarget 7: 52993-53004, 2016.

20. Wang J, Yang S, He P, Schetter AJ, Gaedcke J, Ghadimi BM, Ried T, Yfantis HG, Lee DH, Gaida MM, et al: Endothelial nitric oxide synthase traffic inducer (NOSTRIN) is a negative regulator of disease aggressiveness in pancreatic cancer. Clin Cancer Res 22: 5992-6001, 2016.

21. Basudhar D, Somasundaram V, de Oliveira GA, Kesarwala A, Heinecke JL, Cheng RY, Glynn SA, Ambs S, Wink DA and Ridnour LA: Nitric oxide synthase-2-derived nitric oxide drives multiple pathways of breast cancer progression. Antioxid Redox Signal 26: 1044-1058, 2017.

22. Tang Y, Hou J, Li G, Song Z, Li X, Yang C, Liu W, Hu Y and $\mathrm{Xu}$ Y: ABCG2 regulates the pattern of self-renewing divisions in cisplatin-resistant non-small cell lung cancer cell lines. Oncol Rep 32: 2168-2174, 2014.

23. Noguchi K, Katayama K and Sugimoto Y: Human ABC transporter ABCG2/BCRP expression in chemoresistance: Basic and clinical perspectives for molecular cancer therapeutics. Pharm Genomics Pers Med 7: 53-64, 2014.

24. Lagas JS, van Waterschoot RA, Sparidans RW, Wagenaar E, Beijnen JH and Schinkel AH: Breast cancer resistance protein and P-glycoprotein limit sorafenib brain accumulation. Mol Cancer Ther 9: 319-326, 2010.

This work is licensed under a Creative Commons Attribution-NonCommercial-NoDerivatives 4.0 International (CC BY-NC-ND 4.0) License. 